\title{
Hubungan Pengetahuan Tentang Personal Hygiene pada Remaja Putri Kelas XI Dengan Keputihan di SMK Negeri 3 Medan Tahun 2019
}

\author{
Debby Pratiwi ${ }^{1 *}$, Marlina ${ }^{2}$ \\ ${ }^{1,2}$ Institut Kesehatan Helvetia, Medan, Indonesia \\ *Correspondence email: rayhanprabu0@gmail.com
}

\begin{abstract}
Abstrak. Pendahuluan: Keputihan adalah satu nama penyakit reroduksi kaum wanita, yang berupa keluarnya cairan berwarna putih dari vaginanya, yang berupa lendir. Menurut WHO (World Health Organization) Tahun 2014, hampir seluruh wanita dan remaja pernah mengalami keputihan 60\% pada remaja usia 15-22 tahun dan 40\% pada wanita usia 23-45 tahun. Sekitar 75\% jumlah wanita di dunia pernah mengalami keputihan.Tujuan: untuk mengetahui Hubungan Pengetahuan tentang personal hygiene pada remaja putri dengan keputihan di SMK Negeri 3 Medan. Metode: penelitian bersifat survei analitik, yang menggunakan metode cross sectional. Populasi dalam penelitian ini adalah remaja putri di SMK Negeri 3 Medan yaitu berjumlah 35 responden dan seluruhnya dijadikan sampel penelitian bivariat dengan chi-square dengan menggunakan data primer. Hasil: dari remaja putri yang mengalami keputihan sebanyak 32 responden $(91,4 \%)$ dan yang tidak keputihan sebanyak 3 responden $(8,6 \%)$. Berdasarkan hasil uji statistik disimpulkan bahwa ada hubungan pengetahuan remaja putri tentang personal hygiene dengan keputihan $(\mathrm{p}=0,05<0,000)$.Kesimpulan: ada hubungan pengetahuan remaja putri tentang personal hygiene dengan keputihan di SMK Negeri 3 Medan Tahun 2019
\end{abstract}

Kata Kunci: Pengetahuan Tentang Personal Hygiene; Keputihan

\begin{abstract}
Introduction: Vaginal discharge is one name ills reroduksi women, in the form of a white fluid discharge from the vagina, in the form of mucus. According to the WHO (World Health Organization) in 2014, almost all women and adolescents have experienced vaginal discharge 60\% in adolescents aged 15-22 years and 40\% in women aged $23-45$ years. About $75 \%$ of the number of women in the world have experienced vaginal discharge. The goal: to find out the relationship of knowledge about personal hygiene in young women with vaginal discharge at SMK Negeri 3 Medan However Measure. Method: research survey of analytical nature, which uses a method of cross sectional. The population in this study are young women in SMK Negeri 3 Medan However Measure i.e. totalling 35 respondents research samples made entirely and bivariat with chi-square by using the primary data. Results: from young women who experience vaginal discharge as much as 32 respondents (91.4\%) and not whitish as much as 3 respondents (8.6\%). Based on the results of the statistical tests concluded that there is a relationship of young women about personal hygiene with whitish $(p=0.05<0.000)$. Conclusion: there is a relationship of young women about personal hygiene whiteness in SMK Negeri 3 Medan Year 2019.
\end{abstract}

Keywords: Knowledge About Personal Hygiene; Vaginal Discharge

\section{PENDAHULUAN}

Sebagian besar remaja putri tidak mengetahui tentang Personal Hygiene atau kebersihan alat genetalia nya dengan baik dan benar seperti mengganti celana dalam saat terasa lembab, tidak memakai celana dalam secara berganti dengan orang lain dan mencuci vagina dengan air yang bersih setiap selesai BAB, BAK dan mandi. Karena dengan remaja tidak menjaga kebersihan alat genetalia nya dapat menimbulkan keputihan dan jika tidak ditangani dengan baik dapat menyebabkan Keputihan yang Patologis.

Menurut WHO (World Health Organization) Tahun 2014, hampir seluruh wanita dan remaja pernah mengalami keputihan 60\% pada remaja usia 15-22 tahun dan $40 \%$ pada wanita usia 23-45 tahun. Sekitar $75 \%$ jumlah wanita di dunia pernah mengalami keputihan. (Fenti suryani, 2016)

Data Asia Tahun 2013 penelitian yang pernah dilakukan di Asia Selatan, di daerah Bengal Selatan tentang tingkat pengetahuan kebersihan organ reproduksi pada saat menstruasi dari 160 anak perempuan didapatkan $67,5 \%$ memiliki pengetahuan yang baik sedangkan $97,5 \%$ tidak mengetahui tentang kebersihan reproduksi pada saat menstruasi. (Muin $\mathrm{M}$ et al, 2013)

Kasus keputihan di Indonesia semakin meningkat. Berdasarkan hasil Penelitian menyebutkan bahwa tahun 2010, 52\% wanita mengalami keputihan, kemudian pada tahun 2011, 60\% wanita pernah mengalami keputihan, sedangkan tahun 2012 hampir 70\% wanita di Indonesia pernah mengalami keputihan, dan pada tahun 2013 bulan Januari hingga Agustus hampir 55\% wanita pernah mengalami keputihan. (Fachlevy MDSYAF, 2017)

Berdasarkan Data Dinas Kesehatan Provinsi Sumatera Utara pada Tahun 2013 penderita kanker serviks sebanyak 318 orang. Penderita yang sakit dalam keadaan stadium lanjut, kanker serviks diawali dengan keputihan yang lama tidak diobati dan ditangani dengan baik. (Sibero JT dan Hanum R, 2018)

Dari hasil penelitian Tri Indah Setiani,dkk (2015) yang berjudul Kebersihan Organ Kewanitaan dan 
Kejadian Keputihan Patologi pada Santriwati di Pondok Pesantren Al Munawwir Yogyakarta yaitu dari 98 responden remaja putri berpengetahuan baik tentang personal hygiene yaitu sebanyak 33 responden $(37,1 \%)$ berpengetahuan cukup sebanyak 30 responden $(33,7 \%)$ dan berpengetahuan kurang sebanyak 26 responden $(29,2 \%)$, Mayoritas mengalami keputihan patologis yaitu sebanyak 53 responden $(59,6 \%)$ dan Minoritas yang mengalami Keputihan Fisiologis yaitu sebanyak 36 orang $(40,4 \%)$. (Indah Setiani T, 2015)

Keputihan adalah keluarnya cairan selain darah dari liang vagina diluar kebiasaan, baik berbau, ataupun tidak, serta disertai rasa gatal setempat. Penyebab keputihan dapat secara normal (fisiologis) yang dipengaruhi oleh hormon tertentu. Cairannya berwarna putih, tidak berbau, dan jika dilakukan pemeriksaan laboratorium tidak menunjukkan ada kelainan. (Kusmiran E, 2013)

Pengertian Personal Hygiene berasal dari bahasa Yunani, yang berarti Personal yang artinya perorangan dan Hygiene berarti sehat. Kebersihan perorangan adalah suatu tindakan untuk memelihara kebersihan dan kesehatan seseorang untuk kesejahteraan fisik maupun psikis. (Yuni Erlina N, 2016)

\section{METODE}

Jenis penelitian ini adalah survey analitik dengan metode Cross Sectional yaitu suatu penelitian untuk mempelajari dinamika kolerasi antara faktor-faktor risiko dengan efek, dengan cara pendekatan, observasi atau pengumpulan data. Hal ini berarti semua objek penelitian diamati pada waktu yang sama.

Teknik pengumpulan data yang digunakan adalah data primer yaitu data yang diperoleh oleh peneliti dengan melakukan wawancara kepada remaja putri di SMK Negeri 3 Medan. Dalam penelitian ini peneliti menggunakan metode angket dengan menggunakan alat bantu kuesioner dan memberi tanda check list pada jawaban yang menurut responden benar, dalam angket diawasi oleh peneliti.

Data sekunder adalah data yang diperoleh dengan cara melihat catatan atau dokumen sekolah di SMK
Negeri 3 Medan yang berupa data absensi siswa kelas XI pada Tahun 2019.

Analisa data dengan mendistribusikan variabel pengetahuan tentang personal hygienepada remaja puteri dengan keputihan yang disajikan dalam bentuk tabel distribusi frekuensi.

Analisis bivariat digunakan untuk mengetahui apakah ada hubungan pengetahuan tentang personal hygiene pada remaja puteri dengan Keputihan. Dalam analisa bivariat dilakukan dengan bentuk frekuensi dan persen dengan menggunakan statistic Chi-square. (Muhammad I, 2016)

Pengertian Personal Hygiene berasal dari bahasa Yunani, yang berarti Personal yang artinya perorangan dan Hygiene berarti sehat. Kebersihan perorangan adalah suatu tindakan untuk memelihara kebersihan dan kesehatan seseorang untuk kesejahteraan fisik maupun psikis. (Yuni Erlina N, 2016)

\section{HASIL DAN PEMBAHASAN}

Tabel 1. Distribusi Frekuensi Pengetahuan Remaja Putri Tentang personal hygiene di SMK Negeri 3 Medan Tahun 2019

\begin{tabular}{|c|c|c|}
\hline \multirow{2}{*}{ Variabel Independen } & \multicolumn{2}{|c|}{ Jumlah } \\
\hline & $\mathbf{F}$ & $\%$ \\
\hline \multicolumn{3}{|c|}{ Pengetahuan Remaja Putri Tentang Personal Hygiene } \\
\hline Baik & 6 & 17,1 \\
\hline Cukup & 6 & 17,1 \\
\hline Kurang & 23 & 65,7 \\
\hline \multicolumn{3}{|l|}{ Keputihan } \\
\hline Mengalami & 32 & 91,4 \\
\hline Tidak Mengalami & 3 & 8,6 \\
\hline
\end{tabular}

Berdasarkan tabel diatas dapat diketahui bahwa pengetahuan remaja putri tentang personal hygiene yaitu dari 35 responden yang berpengetahuan baik sebanyak 6 responden $(17,1 \%)$, berpengetahuan cukup sebanyak 6 responden $(17,1 \%)$ dan berpengetahuan kurang 23 responden $(65,7 \%)$.

Berdasarkan tabel diatas dapat diketahui bahwa dari 35 responden, Mengalami keputihan sebanyak 32 responden $(91,4 \%)$ dan yang tidak mengalami keputihan sebanyak 3 responden $(8,6 \%)$.

Tabel 2. Tabulasi Silang Hubungan Pengetahuan Remaja Putri Tentang Personal Hygiene Dengan Keputihan di SMK Negeri 3 Medan Tahun 2019

\begin{tabular}{|c|c|c|c|c|c|c|c|}
\hline \multirow{3}{*}{$\begin{array}{c}\text { Pengetahuan Remaja Putri Tentang } \\
\text { Personal Hygiene }\end{array}$} & \multicolumn{4}{|c|}{ Keputihan } & \multirow{2}{*}{\multicolumn{2}{|c|}{ Jumlah }} & \multirow{3}{*}{ Sig p } \\
\hline & \multicolumn{2}{|c|}{ Mengalami } & \multicolumn{2}{|c|}{ Tidak mengalami } & & & \\
\hline & $\mathbf{f}$ & $\%$ & $\mathbf{f}$ & $\%$ & $\mathbf{F}$ & $\%$ & \\
\hline Baik & 6 & 17,1 & 0 & 0 & 6 & 17,1 & \\
\hline Cukup & 3 & 8,6 & 3 & 8,6 & 6 & 17,1 & 0,000 \\
\hline Kurang & 23 & 65,7 & 0 & 0 & 23 & 65,7 & \\
\hline Total & 32 & 91,4 & 3 & 8,6 & 35 & 100 & \\
\hline
\end{tabular}

Berdasarkan tabel diatas dapat diketahui bahwa tabulasi silang antara hubungan pengetahuan remaja putri tentang personal hygiene dengan keputihan, yaitu dari 35 responden, berpengetahuan baik sebanyak 6 responden $(17,1 \%)$ yang mengalami keputihan sebanyak 6 responden $(17,1 \%)$ dan yang tidak mengalami 
keputihan sebanyak 0 responden $(0 \%)$, berpengetahuan cukup sebanyak 6 responden $(17,1 \%)$ yang mengalami keputihan sebanyak 3 responden $(8,6 \%)$ dan yang tidak mengalami keputihan sebanyak 3 responden $(8,6 \%)$ dan berpengetahuan kurang sebanyak 23 responden $(65,7 \%)$ yang mengalami keputihan sebanyak 23 responden $(65,7 \%)$ yang tidak mengalami keputihan 0 responden $(0 \%)$.

Berdasarkan hasil analisis dengan uji Chi-Square diperoleh bahwa Sig-P 0,000<0,05 berarti Ha diterima, sehingga ada Hubungan Pengetahuan Remaja Putri Tentang Personal Hygiene dengan Keputihan Di SMK Negeri 3 Medan Tahun 2019.

\section{Pembahasan}

Keputihan adalah satu nama penyakit reroduksi kaum wanita, yang berupa keluarnya cairan berwarna putih dari vaginanya, yang berupa lendir. Kadangkadang lendir yang keluar dari vagina berbau busuk, namun kadang-kadang tidak begitu berbau sama sekali. (Syadam SG, 2015)

Pengertian Personal Hygiene berasal dari bahasa Yunani, yang berarti Personal yang artinya perorangan dan Hygiene berarti sehat. Kebersihan perorangan adalah suatu tindakan untuk memelihara kebersihan dan kesehatan seseorang untuk kesejahteraan fisik maupun psikis. (Yuni Erlina N, 2016)

Berdasarkan hasil penelitian menunjukkan tabulasi silang antara hubungan pengetahuan remaja putri tentang personal hygiene dengan keputihan dari 35 responden, berpengetahuan baik sebanyak 6 responden $(17,1 \%)$ yang mengalami keputihan sebanyak 6 responden $(17,1 \%)$ dan yang tidak mengalami keputihan sebanyak 0 responden $(0 \%)$, berpengetahuan cukup sebanyak 6 responden $(17,1 \%)$ yang mengalami keputihan sebanyak 3 responden $(8,6 \%)$ dan yang tidak mengalami keputihan sebanyak 3 responden $(8,6 \%)$ dan berpengetahuan kurang sebanyak 23 responden $(65,7 \%)$ yang mengalami keputihan sebanyak 23 responden $(65,7 \%)$ dan yang tidak mengalami keputihan 0 responden $(0 \%)$.

Berdasarkan uji Chi-Square 0,000 yang menunjukkan bahwa ada Hubungan Pengetahuan Remaja Putri Tentang Personal Hygiene Dengan Keputihan Di SMK Negeri 3 Medan.

Flour albus ini menimbulkan ketidaknyamanan dan gangguan rasa percaya diri pada wanita bila terlalu berlebihan. Flour albus fisiologis tidak merugikan karena hal itu wajar terjadi tetapi Flour albus yang patologis dan berlebihan perlu dicari penyebabnya karena dapat menimbulkan komplikasi. Flour albus patologis biasanya keluar berlebihan dari ringan sampai berat, lebih kental, berbau busuk, menimbulkan rasa gatal dan berwarna kuning sampai kehijauan. Flour albus patologi dapat timbul karena radang yang disebabkan trikomoniasis, kandidiasis, onore, vaginitis senilis, endoservitis akut atau kronis, vaginitis hemofius vaginalis, oleh iritasi zat kimia atau iritasi vagina. (Nurlaila, Z M, 2015)

Berdasarkan hasil penelitian pada Tahun 2015 yang dilakukan oleh Nurlaila yang berjudul "Hubungan Pengetahuan dan Personal Hygiene dengan kejadian keputihan (Flour Albus) pada Remaja Putri di SMP SuryaDarma Lampung" yaitu dari 60 responden mayoritas remaja putri berpengetahuan baik tentang personal hygiene yaitu sebanyak 40 responden $(66,7 \%)$ dan minoritas berpengetahuan tidak baik sebanyak 20 responden $(33,3 \%)$, mayoritas mengalami keputihan yaitu sebanyak 39 responden $(65,0 \%)$ dan minoritas yang mengalami tidak Keputihan yaitu sebanyak 21 orang $(35,0 \%)$ dengan hasil uji chi-square $\mathrm{p}=0,01<0,05$. (Nurlaila, Z M, 2015)

Menurut asumsi peneliti, bahwa dari 35 responden terdapat 23 berpengetahuan kurang $(65,7 \%)$ semua mengalami keputihan serta 6 yang berpengetahuan cukup $(17,1 \%)$ terdapat 3 yang mengalami keputihan dan 3 yang tidak mengalami keputihan, juga terdapat $6(17,1 \%)$ dengan pengetahuan baik yang mengalami keputihan, karena remaja yang memiliki pengetahaun baik tidak menjamin untuk tidak mengalami keputihan. Karena banyak dari remaja putri yang kurang menjaga kebersihannya karena beralasan mereka tidak tahu bagimana cara menjaga kebersihan seperti tidak boleh mencuci vagina secara sembarangan tetapi mencuci dari depan kebelakang serta banyak remaja yang tidak menjaga kebersihan pada saat haid karena remaja hanya menganti pembalut saat sudah penuh atau bocor sehingga menyebabkan timbulnya kuman atau jamur penyebab keputihan. Hasil penelitian ini dapat dilihat bahwa banyak remaja yang kurang memiliki pengetahuan dan dari hasil penelitian terdahulu oleh Nurlaila dapat dilihat bahwa hasil berbanding sama yaitu banyak remaja yang tidak mengetahui tentang personal hygiene sehingga mengalami keputihan.

\section{SIMPULAN}

Ada Hubungan Pengetahuan Remaja Putri Tentang Personal Hygiene Dengan Keputihan Di SMK Negeri 3 medan Tahun 2019 dengan hasil uji statistik menggunakan uji chi-square diperoleh bahwa sig-p $0,000<0,05$. Diharapkan pada remaja putri agar lebih meningkatkan pengetahuan dan wawasan tentang keputihan, dan lebih giat lagi mencari informasi khususnya tentang keputihan.

\section{DAFTAR PUSTAKA}

Fenti suryani. Pengetahuan Remaja Tentang Vulva Hygiene Terhadap Kejadian Keputihan. 2016;

Fachlevy MDSYAF. Hubungan Pengetahuan, Vulva Hygiene, Stres , dan Pola Makan dengan Kejadian Infeksi Flour Albus (keputihan) pada Remaja Siswi SMA Negeri 6 Kendari 2017. Jimkesmas. 
2017;2(6).

Indah Setiani T, Prabowo T, Paramita DP. Kebersihan Organ Kewanitaan dan Kejadian Keputihan Patologi pada Santriwati di Pondok Pesantren Al Munawwir Yogyakarta. J Ners dan Kebidanan Indones [Internet]. 2015;3(1). Available from: http://ejournal.almaata.ac.id/index.php/JNKI/articl e/view/98

Kusmiran E. Kesehatan Reproduksi Remaja dan Wanita. Jakarta: Salemba Medika; 2013.

Muhammad I. Panduan karya tulis ilmiah. 5th ed. Medan: Citapustaka Media Perintis; 2016.

Muin M, Salmah U, Sarake M. Hubungan Pengetahuan Penyakit Menular Seksual (PMS) Dengan Tindakan Kebersihan Alat Reproduksi Eksternal Remaja Putri Di SMA Nasional Makassar Tahun 2013. Jurbal FKM UNHAS. 2013;1-12.

Nurlaila, Z M. Hubungan pengetahuan dan personal hygiene dengan kejadian keputihan (. 2015;XI(1)

Sibero JT, Hanum R. DENGAN PEMERIKSAAN IVA DI PUSKESMAS HAMPARAN PERAK KABUPATEN DELI SERDANG 2017. 2018;IV(7):10-8.

Syadam SG. Waspadai Penyakit Reproduksi Anda. 2nd ed. Bandung: Penerbit Pustaka Reka Cipta; 2015

Yuni Erlina N. Buku Saku Personal Hygiene. 2nd ed. Yogyakarta: Nuha Medika; 2016. . 